\title{
Effect of storage conditions on the biogenic amine content in wild boar meat
}

\author{
Zdeňka Hutařová ${ }^{1}$, Gabriela Bořilová$^{2}$, Irena Svobodová ${ }^{2}$, Vladimír Večerek ${ }^{1}$, \\ Pavel Forejtek ${ }^{1}$, Radka Hulánková ${ }^{3}$, Petr Maršálek ${ }^{1}$
}

University of Veterinary and Pharmaceutical Science Brno, Faculty of Veterinary Hygiene and Technology, ${ }^{1}$ Department of Veterinary Public Health and Animal Welfare, ${ }^{2}$ Department of Meat Hygiene and Technology, Brno, Czech Republic

Received November 25, 2013

Accepted January 23, 2014

\begin{abstract}
Hygienic quality of game meat depends on many factors during and after hunting. Freshness of meat is connected with the concentration of biogenic amines which is related to meat spoilage. The aim of this study was to assess changes in concentration of biogenic amines in raw meat of wild boar ( $n=20$, mean age $1-2$ years) during storage at different temperatures. Carcases of wild boars hunted in winter 2012 in hunting districts of south Moravia were stored unskinned during 21 days at various temperatures $\left(0,7\right.$ and $\left.15^{\circ} \mathrm{C}\right)$. Concentrations of biogenic amines (putrescine, cadaverine, tyramine, tryptamine, phenylethylamine, histamine, spermine and spermidine) were determined in the shoulder and leg muscles by high-performance liquid chromatography in combination with triple quadrupole tandem mass spectrometry. Good hygienic quality was maintained when wild boar carcasses were stored for a maximum of 14 days at $0{ }^{\circ} \mathrm{C}$ (content of biogenic amines in 3 meat samples exceed the limit of $5 \mathrm{mg} / \mathrm{kg}$ on day 21 of storage) or a maximum of 7 days at $7{ }^{\circ} \mathrm{C}$ (content of biogenic amines in 4 meat samples exceed the limit of $5 \mathrm{mg} / \mathrm{kg}$ on day 14 of storage). The temperature of $15^{\circ} \mathrm{C}$ should be considered as unsuitable storage temperature if good hygienic quality of game meat during storage is to be guaranteed (content of biogenic amines in 2 meat samples exceed the limit of $5 \mathrm{mg} / \mathrm{kg}$ already on day 7 of storage). The study brings new information about the biogenic amine content and its changes in wild boar meat during the storage period of 21 days.
\end{abstract}

Cadaverine, hygienic quality, putrescine, temperature, venison

Game meat quality depends on many factors ranging from hunting to meat processing and its storage. They all affect the hygienic quality of game meat and thus may pose a health risk for final consumers. Meat contaminating bacteria usually transfer from the digestive tract or the skin of the carcass during slaughter. It is therefore advisable to monitor selected bacterial groups and determine the biogenic amines in meat in order to detect incipient spoilage. Their quantity can relate to meat freshness (Membre et al. 2011).

Hernandez-Jover et al. (1996) proposed the following limits for contents of biogenic amines (the sum of putrescine, cadaverine, tyramine and histamine) in meat for the assessment of hygienic quality: $<5 \mathrm{mg} / \mathrm{kg}$ for good quality fresh meat, $5-20 \mathrm{mg} / \mathrm{kg}$ for meat of acceptable hygienic quality, but with initial signs of spoilage, $20-50 \mathrm{mg} / \mathrm{kg}$ for meat of low hygienic quality and $>50 \mathrm{mg} / \mathrm{kg}$ for spoiled meat. To protect consumer health, it is very important to monitor the concentration of biogenic amines in food because they can lead to symptoms such as nausea, headache, rash and changes in blood pressure (Ladero et al. 2012). The presence of the spermine and spermidine polyamines found in animal bodies has been described as physiological (Hernandez-Jover et al. 1997; Silva and Gloria 2002; Balamatsia et al. 2006) and not associated with spoilage (HernandezJover et al. 1997).

Game meat ranks among highly appreciated foods (Hoffman and Wiklund 2006). Information is available about the hygienic quality of the game meat and also about the 
content of biogenic amines in venison, e.g. pheasant meat (Paulsen et al. 2008; Hutarova et al. 2013a, 2013b, 2013c) and meat from wild ducks (Hutarova et al. 2013). In spite of an increasing population of wild boar in Europe, relatively very few studies focus on the quality of wild boar meat and its products (Paulsen et al. 2011).

The aim of this study was to assess changes in the concentration of biogenic amines in raw meat of wild boar stored at different temperatures, and to use the results for the assessment of meat hygienic quality.

\section{Wild boar}

\section{Materials and Methods}

In the study, 20 carcasses of wild boar killed by hunters during the winter 2012 in individual or collective hunting in the Czech Republic were used. The mean age of wild boar was 1-2 years, and their body weight ranged between $18-39 \mathrm{~kg}$. The carcasses of the boars were divided into 3 groups and stored eviscerated and unskinned for 21 days at different temperatures. The wild boar from the first group ( 8 carcasses) were stored at $0{ }^{\circ} \mathrm{C}$, the second group ( 6 carcasses $)$ at $7^{\circ} \mathrm{C}$ and the third group $(6$ carcasses $)$ at $15^{\circ} \mathrm{C}$. The storage temperature of $0{ }^{\circ} \mathrm{C}$ was chosen for the monitoring of biogenic amine concentrations in wild boar meat during storage under optimum temperature conditions (EU legislation - Regulation (EC) 853/2004 - game meat should be stored at temperatures below $4{ }^{\circ} \mathrm{C}$ ). The temperature of $7{ }^{\circ} \mathrm{C}$ was chosen in order to test game meat that is stored and sold in small quantities either directly to the final consumer or to some retail establishments or shops (legislation of some EU member states). The temperature of $15{ }^{\circ} \mathrm{C}$ simulates cases of gross violation of storage temperature conditions.

Muscle tissues of one hind leg and one shoulder from each stored carcass were collected at weekly intervals. On storage day 1 (storage temperature of $0{ }^{\circ} \mathrm{C}$ ), 8 samples from 2 carcasses were collected ( 4 shoulders and 4 hind legs). On storage days 7, 14, and 21 (temperature of 0,7 and $\left.15^{\circ} \mathrm{C}\right), 8$ samples ( 4 shoulders and 4 hind legs) from 4 carcasses from each of 3 groups and period of storage were collected.

\section{Chemical analysis}

Concentrations of biogenic amines (putrescine, cadaverine, tyramine, tryptamine, histamine, phenylethylamine, spermine and spermidine) were determined in each sample collected from the muscles. To ensure the representativeness of samples, the collected muscles from each body part (shoulder and hind leg) were separately pureed. From the homogenised material, the amount of $0.5 \mathrm{~g}$ was consequently withdrawn for biogenic amines assessment. One-step extraction using mixtures of trichloracetic acid in water (5\%) followed by clean-up step using a $0.45 \mu \mathrm{m}$ syringe filter was employed for sample preparation. Biogenic amines were subsequently separated by reverse phase liquid chromatography using $\mathrm{C}_{18}(2.1 \mathrm{~mm} \times 50 \mathrm{~mm}, 1.9 \mu \mathrm{m}$; Thermo, San Jose, CA, USA) column and detected by tandem mass spectrometry using a heated electro spray-ionization in positive ion mode. Thermo Scientific UHPLC Accela 1250 system was connected to a Thermo Scientific TSQ Quantum Access MAX Triple Quadrupole Instrument (Thermo, San Jose, CA, USA).

\section{Statistical analysis}

A total concentration of biogenic amines (the sum of putrescine, cadaverine, tyramine, histamine, tryptamine and phenylethylamine) in individual samples was calculated. Contrary to the method by Hernandez-Jover et al. (1996), which used only four biogenic amines (putrescine, cadaverine, tyramine and histamine) in their study, we used also phenylethylamine and tryptamine because of their presence in concentrations comparable to histamine. From values of individual samples, the mean and standard deviation were calculated for every period of storage and appropriate temperature. The number of samples in which the total biogenic amine concentration exceeded $5 \mathrm{mg} / \mathrm{kg}$ was also determined for every period of storage and appropriate temperature. Differences in total biogenic amine concentrations in individual storage periods for each storage temperature were evaluated using the UNISTAT 5.6 statistical software. Data were subjected to a Kruskal-Wallis ANOVA (because of non-normal distribution of data) and subsequently to a non-parametric Tukey-type multiple comparisons test with ranked sums in order to assess differences between all possible pairs of groups. The mean difference was considered significant at $P<0.01$

\section{Results}

The total biogenic amine content (the sum of putrescine, cadaverine, histamine, tyramine, phenylethylamine and tryptamine) in unskinned wild boar meat in the course of 21 days of storage at temperatures of $0{ }^{\circ} \mathrm{C}, 7^{\circ} \mathrm{C}$ and $15^{\circ} \mathrm{C}$ is shown in Table 1 . Compared to the first day of storage, a significant $(P<0.01)$ increase in the concentration of biogenic amines was observed on day 21 (increase from $1.18 \mathrm{mg} / \mathrm{kg}$ to $4.76 \mathrm{mg} / \mathrm{kg}, P<0.01$ ) at the temperature of $0{ }^{\circ} \mathrm{C}$ and on day 14 (increase from $1.18 \mathrm{mg} / \mathrm{kg}$ to $7.65 \mathrm{mg} / \mathrm{kg}$ ) at the temperature of 
Table 1. The total biogenic amine content (the sum of putrescine, cadaverine, histamine, tyramine, phenylethylamine and tryptamine) in wild boar meat.

\begin{tabular}{|c|c|c|c|}
\hline \multirow{2}{*}{ Day of storage } & \multicolumn{3}{|c|}{ Storage temperature } \\
\hline & $0{ }^{\circ} \mathrm{C}$ & $7^{\circ} \mathrm{C}$ & $15^{\circ} \mathrm{C}$ \\
\hline 1 & $1.18 \pm 0.11$ & $1.18 \pm 0.11$ & $1.18 \pm 0.11$ \\
\hline 7 & $1.86 \pm 1.02$ & $1.43 \pm 0.28$ & $4.50 \pm 2.69$ \\
\hline 14 & $1.63 \pm 0.48$ & $7.65 \pm 9.20^{*}$ & $21.03 \pm 19.15^{*}$ \\
\hline 21 & $4.76 \pm 5.12^{*}$ & $4.40 \pm 4.15$ & $28.98 \pm 14.96^{*}$ \\
\hline
\end{tabular}

Data are expressed as mean $\pm \mathrm{SD}$. *Significant difference compared to the first day of storage.

$7{ }^{\circ} \mathrm{C}$. The carcasses of wild boar stored at $15{ }^{\circ} \mathrm{C}$ showed an increase in biogenic amine concentrations already after storage day 1 (increase from $1.18 \mathrm{mg} / \mathrm{kg}$ to $4.5 \mathrm{mg} / \mathrm{kg}$ ) with a subsequent significant $(P<0.01)$ increase after storage day 7 (increase to $21.02 \mathrm{mg} / \mathrm{kg}$ ).

Spermine and spermidine concentrations, elevated from the beginning of storage, showed no significant changes throughout the whole storage period.

\section{Discussion}

Concentrations of the spermine and spermidine polyamines assessed in wild board meat in our study were found at elevated concentrations from the first storage day without major changes during storage. Similar results have been reported by Krausova et al. (2006) who determined spermine and spermidine concentrations in pork $24 \mathrm{~h}$ after slaughter. Concentration of these polyamines is not connected with meat spoilage (HernandezJover et al. 1997); therefore these concentrations were not used for evaluation of meat hygienic quality in our study.

Evaluation of the hygienic quality of wild boar meat was performed by measuring concentrations of biogenic amines such as putrescine, cadaverine, histamine, tyramine, phenylethylamine and tryptamine.

The results obtained in our study confirm the direct proportion of biogenic amine production and storage temperature; lower production of biogenic amines was detected at lower temperatures of storage (Duflos 2009; Prester et al. 2009; Naila et al. 2011).

Total biogenic amine contents in individual samples of wild boar meat were further used to determine the period for which wild boar meat can be stored while meeting the conditions for meat of good hygienic quality (the sum of biogenic amine concentrations less than $5 \mathrm{mg} / \mathrm{kg}$ ). The number of samples in which the selected biogenic amines concentration during storage exceeds the limit value of $5 \mathrm{mg} / \mathrm{kg}$ is given in Table 2. Results in Table 2 show that the limit value of $5 \mathrm{mg} / \mathrm{kg}$ was exceeded in some samples of wild boar carcasses

Table 2. The number of wild boar meat samples in which the sum of biogenic amine concentrations exceeded $5 \mathrm{mg} / \mathrm{kg}$.

\begin{tabular}{cccc}
\hline \multirow{2}{*}{ Day of storage } & \multicolumn{3}{c}{ Storage temperature } \\
\cline { 2 - 4 } & $0{ }^{\circ} \mathrm{C}$ & $7{ }^{\circ} \mathrm{C}$ & $15^{\circ} \mathrm{C}$ \\
\hline 1 & $0 / 8$ & $0 / 8$ & $0 / 8$ \\
7 & $0 / 8$ & $0 / 8$ & $2 / 8$ \\
14 & $0 / 8$ & $4 / 8$ & $7 / 8$ \\
21 & $3 / 8$ & $2 / 8$ & $8 / 8$ \\
\hline
\end{tabular}


stored at $0{ }^{\circ} \mathrm{C}$ after 14 days of storage, after 7 days of storage at $7^{\circ} \mathrm{C}$, and after only 1 day of storage at $15^{\circ} \mathrm{C}$. Based on the classification of meat hygienic quality according to the content of biogenic amines suggested by Hernandez-Jover et al. (1996), wild boar meat during storage can be characterized in the following manner. When carcasses are stored at $0{ }^{\circ} \mathrm{C}$, game meat can be considered of good hygienic quality for a period of 14 days (the sum of biogenic amine concentrations was less than $5 \mathrm{mg} / \mathrm{kg}$ ). After that period, total concentrations of biogenic amines in 3 samples were at the level of $5-20 \mathrm{mg} / \mathrm{kg}$ that characterizes meat with initial signs of spoilage. Wild boar meat stored at $7{ }^{\circ} \mathrm{C}$ can be considered of good hygienic quality in terms of biogenic amine concentrations for the first 7 days of storage. After that period of storage, values in excess of $5 \mathrm{mg} / \mathrm{kg}$ (loss of good hygienic quality of meat) were found in 4 samples. Regarding biogenic amines, such game meat can be described as showing initial signs of spoilage. In game meat stored at the temperature of $15^{\circ} \mathrm{C}$, the value of $5 \mathrm{mg} / \mathrm{kg}$ was exceeded in some samples after only the first week of storage (initial signs of spoilage were found in 2 samples). In the next two weeks of storage, biogenic amine concentrations rose above $20 \mathrm{mg} / \mathrm{kg}$ ( 7 samples in the second week of storage, 8 samples in the third week of storage), i.e. in terms of biogenic amine content the game meat was of low hygienic quality).

The results of our study shows, that regarding biogenic amines, wild boar carcasses can be stored while maintaining good hygienic quality of game meat for a maximum of 14 days at $0{ }^{\circ} \mathrm{C}$ or a maximum of 7 days at $7^{\circ} \mathrm{C}$. The temperature of $15^{\circ} \mathrm{C}$ should be considered as absolutely unsuitable storage temperature if good hygienic quality of game meat during storage is to be guaranteed.

\section{Acknowledgements}

This study was financially supported by IGA VFU (Grant number IGA 13/2012/FVHE).

\section{References}

Balamatsia CC, Paleologos EK, Kontominas MG, Sayvaidis IN 2006: Correlation between microbial flora, sensory changes and biogenic amines formation in fresh chicken meat stored aerobically or under modified atmosphere packing at $4{ }^{\circ} \mathrm{C}$ : possible role of biogenic amines as spoilage indicators. Anton van Leeuwen 89 : 9-17

Duflos G 2009: Histamine risk in fishery products. Bul Acad Vet France 162: 241-246

Hernandez-Jover T, Izquierdo-Pulido M, Veciana-Nogues MT, Vidal-Carou MC 1996: Biogenic amine sources in cooked cured shoulder pork. J Agr Food Chem 44: 3097-3101

Hernandez-Jover T, Izquierdo-Pulido M, Veciana-Nogues MT, Marine-Font A, Vidal-Carou MC 1997: Biogenic amine and polyamine contents in meat and meat products. J Agr Food Chem 45: 2098-2102

Hoffman LC, Wiklund E 2006: Game and venison - Meat for the modern consumer. Meat Sci 74: 197-208

Hutarova Z, Forejtek P, Vecerek V, Steinhauserova I, Marsalek P, Borilova G 2013: The effect of treating method of game on the content of biogenic amines in wild duck (Anas platyrhynchos) meat during the course of storage. Eur J Wildl Res DOI 10.1007/s10344-013-0775-y

Hutarova Z, Vecerek V, Marsalek P, Steinhauserova I, Borilova G 2013a: Changes in biogenic amine concentrations in meat of eviscerated pheasants (Phasianus colchicus) during storage at $7^{\circ} \mathrm{C}$. Acta Vet Brno 82: 175-180

Hutarova Z, Vecerek V, Steinhauserova I, Marsalek P, Borilova G 2013b: Effects of storage temperature on biogenic amine concentrations in meat of uneviscerated pheasants (Phasianus colchicus). Acta Vet Brno 82: $61-65$

Hutarova Z, Vecerek V, Steinhauserova I, Marsalek P, Borilova G, Forejtek P 2013c: The effect of treating method of pithed pheasant on the content of biogenic amines in the meat during the course of storage. Poultry Sci 92: 2182-2187

Krausova P, Kalac P, Krizek M, Pelikanova T 2006: Content of polyamines in beef and pork after animal slaughtering. Eur Food Res Technol 223: 321-324

Ladero V, Fernandez M, Calles-Enriquez M, Sanchez-Llana E, Canedo E, Martin MC, Alvarez MA 2012: Is the production of the biogenic amines tyramine and putrescine a species-level trait in enterococci? Food Microbiol 30: $132-138$

Membre JM, Laroche M, Magras C 2011: Assessment of levels of bacterial contamination of large wild game meat in Europe. Food Microbiol 28: 1072-1079 
Naila A, Flint S, Fletcher G, Bremer P, Meerdink G 2010: Control of biogenic amines in food-Existing and emerging approaches. J Food Sci 75: 139-150

Paulsen P, Nagy J, Popelka P, Ledecky V, Marcincak S, Pipova M, Smuldlers FJM, Hofbauer P, Lazar P, Dicakova Z 2008: Influence of storage conditions and shotshell wounding on the hygienic condition of hunted, uneviscerated pheasant (Phasianus colchicus). Poultry Sci 87: 191-195

Paulsen P, Vali S, Bauer F 2011: Quality traits of wild boar mould-ripened salami manufactured with different selections of meat and fat tissue, and with and without bacterial starter cultures. Meat Sci 89: 486-490

Prester L, Macan J, Varnai VM, Orct T, Vukusic J, Kipcic D 2009: Endotoxin and biogenic amine levels in Atlantic mackerel (Scomber scombrus), sardine (Sardina pilchardus) and Mediterranean hake (Merluccius merluciccius) stored at $22^{\circ} \mathrm{C}$. Food Add Cont Part A Chem Anal Control Expo Risk Assess 26: 355-362

Silva CMG and Gloria BA 2002: Bioactive amines in chicken breast and thigh after slaughter and during storage at $4 \pm 1{ }^{\circ} \mathrm{C}$ and chicken-based meat products. Food Chem 78: 241-248 